\title{
Belowground herbivore tolerance involves delayed overcompensatory root regrowth in maize
}

\author{
Christelle A.M. Robert ${ }^{1,2}$, Stefanie Schirmer ${ }^{2}$, Julie Barry ${ }^{3}$, B. Wade French ${ }^{4}$, \\ Bruce E. Hibbard ${ }^{3}$ \& Jonathan Gershenzon ${ }^{2}$ \\ ${ }^{1}$ Biotic Interactions, Institute of Plant sciences, University of Bern, Altenbergrain 21, 3013 Bern, Switzerland, ${ }^{2}$ Department of \\ Biochemistry, Max Planck Institute for Chemical Ecology, Hans-Knöll-Str. 8, 07745 Jena, Germany, ${ }^{3}$ USDA-ARS, \\ University of Missouri, Plant Genetics Research University, 205 Curtis Hall, Columbia, MO 65211, USA, and ${ }^{4}$ USDA-ARS, \\ North Central Agricultural Research Laboratory, Brookings, SD, USA
}

Accepted: 1 July 2015

Key words: Diabrotica virgifera, Zea mays, root feeder, root behavior, root growth timing, western corn rootworm, Poaceae, Coleoptera, Chrysomelidae

\begin{abstract}
Plants can tolerate leaf-herbivore attack through metabolic reconfigurations that allow for the rapid regrowth of lost leaves. Several studies indicate that root-attacked plants can re-allocate resources to the aboveground parts. However, the connection between tolerance and root regrowth remains poorly understood. We investigated the timing and extent of root regrowth of tolerant and susceptible lines of maize, Zea mays L. (Poaceae), attacked by the western corn rootworm, Diabrotica virgifera virgifera LeConte (Coleoptera: Chrysomelidae), in the laboratory and the field. Infested tolerant maize plants produced more root biomass and even overcompensated for the lost roots, whereas this effect was absent in susceptible lines. Furthermore, the tolerant plants slowed growth of new roots in the greenhouse and in the field 4-8 days after infestation, whereas susceptible plants slowed growth of new roots only in the field and only after 12 days of infestation. The quick response of tolerant lines may have enabled them to escape root attack by starving the herbivores and by saving resources for regrowth after the attack had ceased. We conclude that both timing and the extent of regrowth may determine plant tolerance to root herbivory.
\end{abstract}

\section{Introduction}

The capacity of crops to maintain high yields under adverse environmental conditions is of central importance for sustainable farming. Under herbivore attack, yields can be protected through resistance and tolerance mechanisms. Resistance refers to the capacity of plants to reduce herbivore injury (Howe \& Jander, 2008), whereas tolerance refers to the capacity of plants to maintain productivity upon sustained damage (Strauss \& Agrawal, 1999). One advantage of plant tolerance could be that it would reduce selection pressure on the herbivores and thereby lowers the risk of counteradaptations (Stowe et al., 2000). On the other hand, tolerance mechanisms per se can have a physiological cost to the plant, as they would need to

*Correspondence: Christelle A.M. Robert, Institute of Plant Sciences, Section Biotic Interactions, University of Bern, Altenbergrain 21, CH-3013 Bern, Switzerland. E-mail: christelle.robert@ips.unibe.ch compensate for the herbivore-imposed loss of biomass (Pilson, 2000; Stinchcombe, 2002; Fornoni et al., 2004; but see Mauricio et al., 1997; Agrawal et al., 1999; Boege et al., 2007). Plant tolerance to leaf-herbivore attack has been studied widely. Tolerance responses include the activation of meristematic growth, which can be supported by an increase in photosynthesis (Strauss \& Agrawal, 1999; Schultz et al., 2013). Photoassimilates can also be reallocated to non-attacked tissues for future regrowth (Holland et al., 1996; Babst et al., 2005, 2008; Schwachtje et al., 2006; Henkes et al., 2008; Gómez et al., 2010; Hanik et al., 2010). In many cases, however, leaf attack by small herbivores triggers a decrease in photosynthesis and leads to a depletion of photoassimilates (Machado et al., 2013). Grazing by larger browsers, on the other hand, can lead to overcompensatory growth, in which case plants accumulate more biomass than without herbivory (Paige \& Whitham, 1996). The regular cutting of grasslands for maximal hay production can be seen as an extreme grazing regime that takes advantage of the plant's capacity to 
tolerate tissue removal (Hawkes \& Sullivan, 2001; Borer et al., 2014).

Relatively little is known about the mechanisms that may enable plants to tolerate root-feeding insects. Root herbivores are among the most important pests in a number of crops. Due to their secluded life style, they often remain difficult to combat with traditional means and have been studied in much less detail than their leaf counterparts (Hunter, 2001; Erb et al., 2013). Field studies of maize and its most devastating root pest, the western corn rootworm, Diabrotica virgifera virgifera LeConte (Coleoptera: Chrysomelidae), have documented that certain maize varieties are able to maintain high productivity after being injured by D. virgifera (Prischmann et al., 2007), pointing to the presence of effective tolerance mechanisms. A ${ }^{13} \mathrm{C}$-labeling approach revealed marginally increased allocation of photosynthates to the aboveground parts of D. virgifera-attacked maize (Xue et al., 2012). Using ${ }^{11} \mathrm{C}$ as a tracer revealed that attacked maize seedlings allocated significantly more carbon to the stems, an effect which was associated with an increase in stem thickness and increased crown root growth (Robert et al., 2014). It is, therefore, conceivable that maize tolerates $D$. virgifera attack through carbon reallocation followed by compensatory growth. Furthermore, a study on Centaurea maculosa Lamarck showed that the plant increases nitrogen $(\mathrm{N})$ allocation to the shoot when attacked by the root feeder Agapeta zoegana L. (Newingham et al., 2007), which indicates that $\mathrm{N}$ reallocation may also help plants to cope with root attack.

For root herbivore tolerance, the timing of regrowth may be an important parameter. Diabrotica virgifera for instance has a strong preference for young crown roots (Robert et al., 2012a,b), and often prunes them directly after they penetrate the soil surface. Hence, immediate regrowth following attack may backfire on the plant by improving $D$. virgifera larval survival and vigor. A desirable regrowth program could instead involve a delay that saves the resources for root reestablishment until the larvae have died or pupated. To date, little is known about the importance of regrowth timing for root herbivore tolerance.

In this study, we investigated the regrowth patterns of susceptible and tolerant maize lines following $D$. virgifera attack in the field and the glasshouse. Using segregating genetic populations that were enriched in tolerance or susceptibility alleles, we tested three phenological hypotheses regarding the potential mechanisms of tolerance. We tested whether (1) tolerant maize lines compensate for root loss by regrowing more strongly below ground; (2) the differences in regrowth are associated with morphological changes in the stems as potential carbohydrate storage organs; and (3) there are differences in the timing of regrowth between tolerant and susceptible lines. Together, our experiments paint a detailed picture of the phenotypical traits that are involved in root herbivore tolerance and reveal that both timing and extent of regrowth are associated with the maintenance of crop productivity under root herbivore attack.

\section{Materials and methods}

\section{Plants and insects}

We used maize plants of the CRW17 population. The intent of the CRW17 population was to conduct a recurrent selection maize breeding program by selecting the ears from least damaged lines, bulk pollinating nursery rows (Ball, 1969) of the selected ears, and evaluating again in a new cycle of selection as was done for CRW3 by Hibbard et al. (2007). Development of this population began in 2007 by using 17 of the lines least damaged by D. virgifera (based on 15 years of evaluating thousands of maize lines) in a diallel scheme. The 17 lines ('founders') originated from several germplasm groups, most of which had more than one representative. Parental materials of the diallel included selections derived from the CRW3 population (Hibbard et al., 2007), from Germplasm Enhancement of Maize materials (Salhuana \& Pollak, 2006), and from BS19 and BS20 (Ball, 1969; Russell et al., 1976). A balanced bulk set of seed from the diallel cross was planted in 2008 for initial recombination. Delayed plantings of this bulk insured that the variable flowering crosses were combined. A second balanced bulk seed set was created and recombined a second time in 2009. Finally, 300 selfed ears from the 2009-2010 winter nursery were selected as CRW17(C0). Nine kernels from each ear were planted in $1.5-\mathrm{m}$ plots in two locations near Columbia (MO, USA) as well as one location near Brookings (SD, USA) in 2010 (BE Hibbard, J Barry \& S FlintGarcia, unpubl.). Four roots from each plot were considered as one replication and each was evaluated for plant injury (Oleson et al., 2005) as well as root regrowth and root size (Rogers et al., 1975). Plant injury is a linear rating scale and uses the following criteria: $0=$ no root injury, 1 = one node of roots eaten, 2 = two nodes eaten, $3=$ three nodes eaten (Oleson et al., 2005). Root size and compensatory root growth were evaluated using six rating scales ( 1 = largest, 6 = smallest; Rogers et al., 1977). Ears chosen for the current work were made with selections based upon consistent regrowth ratings. Three tolerant lines (significant regrowth after herbivory) CRW17-096, CRW17-101, and CRW209, as well as two susceptible lines (no regrowth after herbivory) CRW17-057 and CRW17-069 were used. 
Diabrotica virgifera eggs were kindly provided by the USDA-ARS Columbia (MO, USA) and USDA-ARSNACRL Brookings (SD, USA). Eggs were maintained in their oviposition dishes and stored in a growth chamber at $25{ }^{\circ} \mathrm{C}$ and $60 \%$ r.h. until needed. For greenhouse experiments, eggs were allowed to hatch and larvae reared on freshly germinated maize seedlings until use. Hatching of the eggs in the field was determined by keeping eggs in the laboratory and larval development was traced using soil temperatures as described in Jackson \& Elliott (1988) and Hibbard et al. (2008).

\section{Greenhouse experiment}

Maize seeds were sown in 1-1 plastic pots (Pöppelmann, Lohne, Germany) containing a layer of moist washed sand (0-4 mm grain size; Hagebaumarkt Leipzig, Leipzig, Germany) covered with $2 \mathrm{~cm}$ of commercial soil (Tonsubstrat, Geeste, Germany; Ricoter Aussaaterde, Aarberg, Switzerland). Seedlings were grown in a greenhouse at $23 \pm 12{ }^{\circ} \mathrm{C}, 60 \%$ r.h., and L16:D8 h photoperiod. Fertilizer (Ferty 3; Ferty, Regenstauf, Germany) was added twice a week after seed germination. Three-week-old plants were infested with 6-s instars for 8 days. The infestation was performed by making two 5 -cm deep and 0.5 -cm diameter holes in the soil, at $2 \mathrm{~cm}$ distance from the maize stem each, in which the larvae were placed. Such larval density allows injury levels relatively comparable to field injury and is commonly used (Robert et al., 2012a,b). Control plants remained uninfested. After this period, all roots were washed with tap water and all larvae were manually removed from infested roots. Maize plants were then replanted in soil. Stem circumference was measured at days 0 (day of infestation), 8, and 16 using a flexible ruler. The emerging crown roots were counted every 4 days post-infestation. Crown roots arose from the stem and were visible above the surface without disturbing the plants. The number of emerging crown roots was expressed in percentage of newly emerged roots compared to the average emerging crown from their respective controls.

\section{Field experiment}

The field experiment was conducted in 2012 at the Bradford Research Extension Center (Columbia, MO, USA). Maize plants (two seeds per plot) were sown on 15 May with $43 \mathrm{~cm}$ spacing between plants and $76 \mathrm{~cm}$ spacing between rows. Plants of the variety Pioneer 33M16 were used as buffer plants. Two rows of buffer plants surrounded each experimental plant to avoid herbivore movement from infested to control plots and prevent edge effects. Two weeks after sowing, seedlings were transplanted where no plant emerged. All experimental plots consisted of one plant. Plants from the various maize lines were randomly placed in the field $(\mathrm{n}=48$ per line). Two weeks later (30 May), half of the plots were infested with 600 D. virgifera eggs each, which corresponds to natural infestation density (Hibbard et al., 2004; Robert et al., 2012a,b). Control plants $(n=24)$ were left uninfested. Eggs from the same batch kept in the greenhouse hatched on 11 June (day 0). Stem circumference and crown root emergence were evaluated every 4 days after egg hatching. Crown root emergence from infested plants was expressed as the percentage of newly emerged roots compared to the average of their respective controls. Injury inflicted by D. virgifera was evaluated 2 weeks after larval hatching by harvesting half of the infested and half of the control plants $(\mathrm{n}=12$ each) and using Oleson's scale (Fuller et al., 1997; Oleson et al., 2005). Root regrowth was recorded 4 weeks after larval hatching by harvesting the remaining plants (12 control and 12 infested plants) and attributing a score for regrowth on a scale from 0 to $6(0=$ no regrowth; $6=$ much regrowth). Larval development was estimated using the model developed by Elliott et al. (1990). First harvest fell within the feeding phase of the larvae, whereas the second harvest fell within the pupation phase. Roots were then dried in a glasshouse with the cooling system turned off for 2 weeks prior to measuring their dry mass.

\section{Statistical analyses}

All statistical analyses were performed using $\mathrm{R}$ software (http://www.R-project.org/). Data were analyzed using a Wald test on a linear mixed model (LMM; function 'lmer', package 'lme4'; Bates et al., 2014) in which the phenotype and the treatment were considered as fixed factors, and the maize line as a random factor. Root damage and percentage of emerging crown roots were $\sqrt{\mathrm{x}}$-transformed for a better model fit. Relevant pairwise comparisons of least squares means (LSMeans) were performed using the function 'lsmeans' (package 'lsmeans'; Lenth \& Hervé, 2015) and the Tukey correction for P values. All LMM results can be found in Tables S1-S7.

\section{Results}

\section{Plant tolerance phenotype}

No difference was found in the root regrowth abilities of the susceptible lines. Similarly, no difference was found in the root regrowth abilities of the tolerant lines. Tolerant and susceptible lines suffered similar injury by the root herbivore $D$. virgifera in the field, suggesting no difference in resistance of the different lines (Figure 1, Table S1). Susceptible and tolerant lines displayed similar root system biomass after 2 weeks of larvae feeding (Figure 2A, Table S2). Yet, 4 weeks after infestation only tolerant 


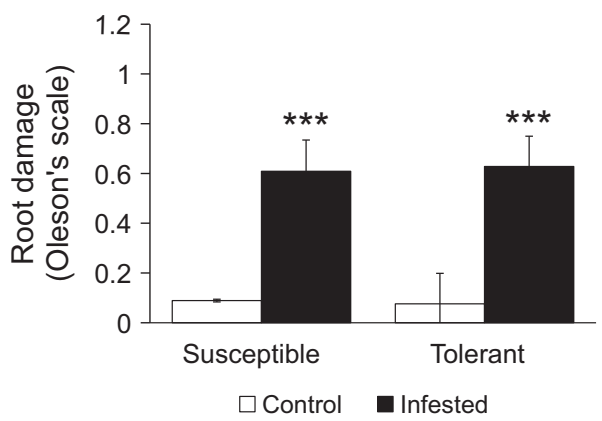

Figure 1 Mean ( \pm SE) root injury (Oleson's scale) of susceptible and tolerant maize lines by the root herbivore Diabrotica virgifera in the field after 2 weeks of herbivory. Asterisks indicate significant differences between infested and control tolerant plants (linear mixed model: $* * * \mathrm{P}<0.001$ ).

plants regrew significantly more biomass (Figure $2 \mathrm{~B}$ ) and roots (Figure 2B and C, Tables S3 and S4). At the end of the experiment ( 4 weeks feeding by the root herbivore), the root systems from infested tolerant plants were almost twice as large (volume and biomass) as the controls (Figure $2 \mathrm{~B}$ and $\mathrm{C}$ ).

\section{Stem circumference}

Susceptible lines did not grow larger stems upon belowground infestation by $D$. virgifera in the field (Figure 3A, Table S5) or in the greenhouse (Figure 3B, Table S6) at any of the measured time points. Tolerant lines displayed significantly larger stems upon infestation in the field at day 12 after larval hatching than control plants (Figure 3C, Table S5). However, it should be noted that this difference is driven by one of the tolerant plant lines only (CRW17C0-101) and that the effect is absent in all lines in the greenhouse (Figure 3D, Table S6).

\section{Crown root emergence}

In the field, both susceptible and tolerant lines reduced the production of crown roots after $D$. virgifera infestation. Susceptible lines grew less crown roots after 12 days of belowground herbivory than their respective uninfested controls (Figure 4A, Table S7). Infested tolerant plants reduced their production of new crown roots significantly after only 8 days of herbivory (Figure 4C), but regrew some by day 12, after 2 weeks of infestation.

In the greenhouse, the same pattern was observed with a reduction in crown root emergence and regrowth occurring in tolerant lines (significant at day 4 after herbivory; Table S8). Yet, no reduction was observed in susceptible lines before regrowth of new roots (Figure 4D).

\section{Discussion}

Our experiments reveal that both the extent and timing of regrowth may function in a synergistic manner to improve plant success under root herbivore attack. Although both tolerant and susceptible maize lines were injured to the same extent by $D$. virgifera, tolerant lines slowed down the
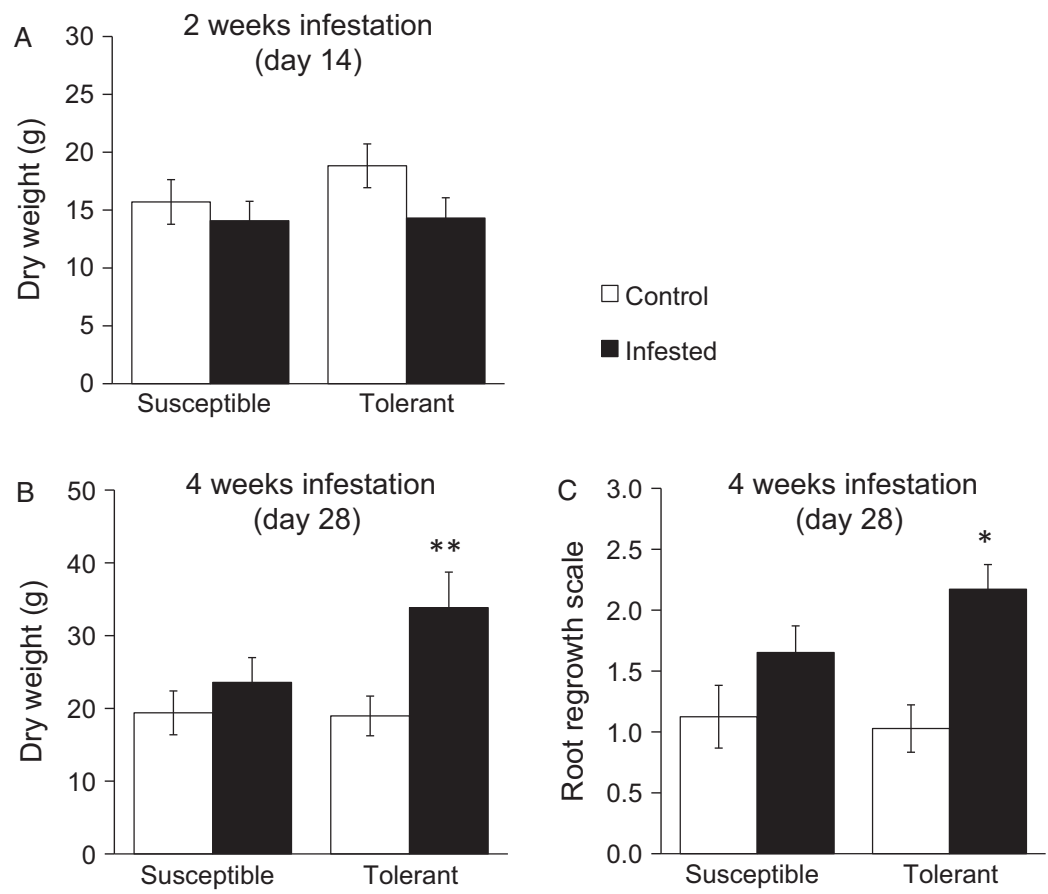

Figure 2 Mean $( \pm S E)$ root system regrowth of (A, B) dry mass $(\mathrm{g})$ and $(\mathrm{C})$ volume of susceptible and tolerant maize varieties upon herbivory by Diabrotica virgifera in the field, 2 and 4 weeks after larval hatching. Asterisks indicate significant differences between infested and control tolerant plants (linear mixed model: $* 0.01<\mathrm{P}<0.05 ; * * \mathrm{P}<0.01)$. 
Figure 3 Mean $( \pm$ SE) stem circumference $(\mathrm{cm})$ upon root herbivory by Diabrotica virgifera in susceptible $(A, C)$ and tolerant maize lines (B, D), in the field $(\mathrm{A}, \mathrm{B})$ and in the greenhouse $(\mathrm{C}, \mathrm{D})$. Asterisk indicates significant differences between infested and control plants (linear mixed model: $* \mathrm{P}<0.05$ ).

Figure 4 Emerging crown roots (mean \pm SE percentage of new roots) upon root herbivory by Diabrotica virgifera in susceptible $(A, C)$ and tolerant maize lines $(\mathrm{B}, \mathrm{D})$, in the field $(\mathrm{A}, \mathrm{B})$ and in the greenhouse $(C, D)$. In each line, the number of emerging crown roots after infestation is expressed as a percentage of the number of emerging crown roots in plants of the same line grown as uninfested controls. Asterisks indicate significant differences between infested and control plants (linear mixed model: ${ }^{*} 0.01<\mathrm{P}<0.05$; $* * \mathrm{P}<0.01)$.
Field
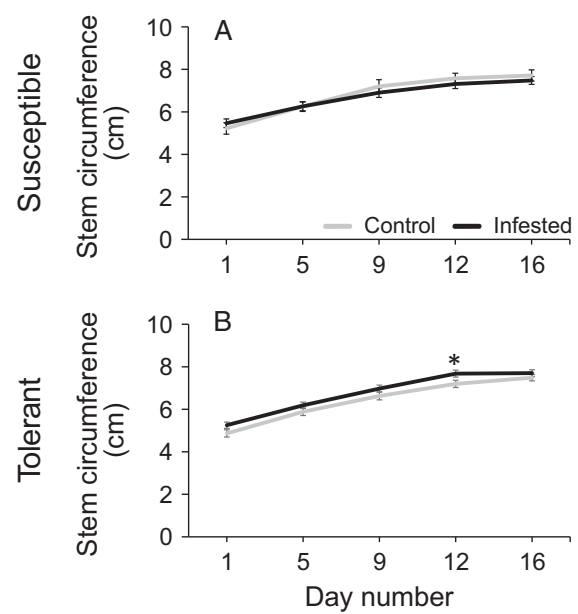

Field
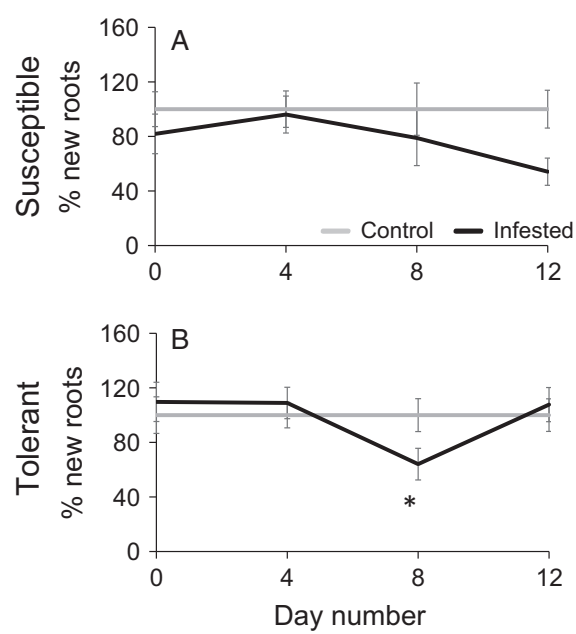

Greenhouse
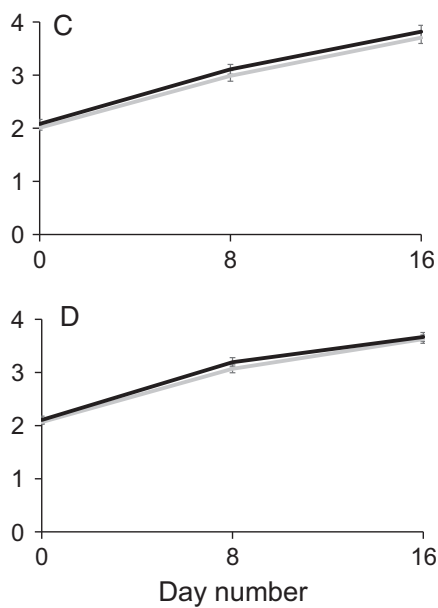

Greenhouse
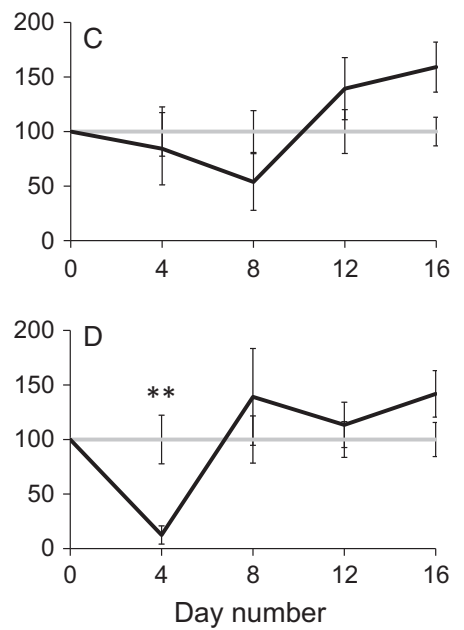

growth of emerging roots early (4-8 days after attack) and regrew significantly more roots 4 weeks after attack, whereas susceptible lines slowed down the emergence of new roots only 12 days after infestation, only in the field, and did not overcompensate after 4 weeks attack. The tolerant population produced more biomass when attacked by $D$. virgifera than controls. This form of overcompensation has been observed in grazed plants before, and it was suggested that grazing may in fact increase rather than decrease plant performance (Dyer, 1975; McNaughton, 1979; Hilbert et al., 1981; Paige \& Whitham, 1996). In the case of roots, it can be expected that overcompensating maize plants maintain or even enhance their capacity to take up water and nutrients from the soil later in the season. In fact, root regrowth after western corn rootworm larval feeding positively affected yield when soil moisture is low, but negatively affected yield when soil moisture was adequate (Gray \& Steffey, 1998). Therefore, and although the impact of similar injury levels on the yield of tolerant and susceptible plants remains to be tested, it is tempting to speculate that maintaining a large root system is an advantage late in the season upon D. virgifera attack, despite the high metabolic investment into root growth.

Aside from biomass overaccumulation, the tolerant maize lines displayed a significant shift in the timing of root regrowth. Although the susceptible population maintained its root system over 8 days of herbivory and reduced its regrowth on day 12 in the field, the tolerant population reduced its regrowth already after 8 days of infestation, and bounced back to control levels by day 12 . A similar pattern was observed under more controlled conditions in the greenhouse, albeit with a slightly earlier response due to direct infestation with L2 larvae compared to starting with hatching eggs in the field. Although 
the physiological mechanism underlying these differences in regrowth timing remain to be determined, we propose that a delayed regrowth may be advantageous for several reasons. First, an initial reduction in belowground growth may starve the $D$. virgifera larvae, which may increase their mortality and potentially their susceptibility to natural enemies. Second, the delayed burst of regrowth may co-occur with the onset of pupation and the end of the feeding phase, thereby increasing the sustainability of the newly produced roots. It is therefore possible that the delayed regrowth is partially responsible for the stronger overaccumulation of root biomass in these lines. However, more detailed experiments are required to link the extent and timing of delayed root regrowth, including tighter experimental control of the timing of larval feeding. Nevertheless, it is tempting to speculate that the tolerant plants may be able to sense and anticipate the development of $D$. virgifera and thereby time their metabolic investment into regrowth.

In an earlier study, we observed that a maize hybrid line attacked by $D$. virgifera showed an increase in stem diameter, which was followed by increased crown root regrowth from the same organ (Robert et al., 2014). In the current experiments, however, we could not detect any effect on stem diameter. Only the stems from the tolerant line CRW17-101 were thicker upon D. virgifera attack from day 0 onwards. This effect remains inconclusive as (1) infested plants possess thicker stems on day 0 in the field (although day 0 in the field is an approximation) and (2) this difference was not found in the greenhouse. Several factors may account for the absence of a clear stem phenotype in the current experiments. First, it is possible that stem thickening is genotype specific, and that none of the lines used in this study display this behavior. Second, the stem phenotype may be visible only in younger plants, and not in the older plants used in the current experiments. As stems elongate and the different nodes move up from the stem base, it becomes more difficult to assess stem thickness as stems become somewhat irregular. From the current experiments, it seems that stem thickening is not a reliable marker of maize tolerance to root herbivory.

In conclusion, our study reveals that tolerant maize plants respond vigorously to root attack by the western corn rootworm with delayed overcompensatory root growth. Although it remains to be determined whether other plant families display similar growth patterns, our results demonstrate how timing and vigor may act together to help plants endure herbivore attack. Given the limited availability of $D$. virgifera resistant maize germplasm, breeding for tolerance may be a promising alternative to reduce the negative impact of this root feeder. The observed growth phenotypes may be useful markers to identify potentially tolerant germplasm in the greenhouse without the need to conduct laborious yield assessments.

\section{Acknowledgements}

We thank Matthias Erb, Matt Higdon, Chad Nielson, and the whole field crew for their kind contribution to field experiments, and Maxime Hervé for statistical support. We are also grateful to the whole Root Herbivore Interactions Group members (MPI-CE) for their help in transplanting the maize plants in the greenhouse. Research activity by CAMR was supported by the Swiss National Science Foundation (PBNEP3_140196). This study was partially supported by a Sinergia grant from the Swiss National Science Foundation (CRSII3_136184).

\section{References}

Agrawal AA, Strauss SY \& Stout MJ (1999) Costs of induced responses and tolerance to herbivory in male and female fitness components of wild radish. Evolution 53: 1093-1104.

Babst BA, Ferrieri RA, Gray DW, Lerdau M, Schlyer DJ et al. (2005) Jasmonic acid induces rapid changes in carbon transport and partitioning in Populus. New Phytologist 167: 63-72.

Babst BA, Ferrieri RA, Thorpe MR \& Orians CM (2008) Lymantria dispar herbivory induces rapid changes in carbon transport and partitioning in Populus nigra. Entomologia Experimentalis et Applicata 128: 117-125.

Ball HJ (1969) Diurnal rhythm of sensitivity to diazinon in adult western corn rootworms. Journal of Economic Entomology 62: 1097-1098.

Bates D, Maechler M, Bolker B \& Walker S (2014) lme4: linear mixed-effects models using Eigen and S4. R package version 1.1-7. Available at: http://CRAN.R-project.org/package $=$ lme4 (accessed May 2015).

Boege K, Dirzo R, Siemens DH \& Brown PD (2007) Ontogenetic switches from plant resistance to tolerance: minimizing costs with age? Ecology Letters 10: 177-187.

Borer ET, Seabloom EW, Mitchell CE \& Cronin JP (2014) Multiple nutrients and herbivores interact to govern diversity, productivity, composition, and infection in a successional grassland. Oikos 123: 214-224.

Dyer M (1975) The effects of red-winged blackbirds (Agelaius phoenicus L.) on biomass production of corn grain (Zea mays L.). Journal of Applied Ecology 12: 719-726.

Elliott NC, Jackson JJ \& Gustin RD (1990) Predicting western corn-rootworm beetle (Coleoptera, Chrysomelidae) emergence from the soil using soil or air-temperature. Canadian Entomologist 122: 1079-1091.

Erb M, Huber M, Robert CAM, Ferrieri AP, Machado RA \& Arce CC (2013) The role of plant primary and secondary metabo- 
lites in root-herbivore behaviour, nutrition and physiology. Advances in Insect Physiology 45: 53-95.

Fornoni J, Valverde PL \& Núñez-Farfán JS (2004) Population variation in the cost and benefit of tolerance and resistance against herbivory in Datura stramonium. Evolution 58: 16961704.

Fuller BW, Boetel MA, Walgenbach DD, Grundler JA, Hein GL et al. (1997) Optimization of soil insecticide rates for managing corn rootworm (Coleoptera: Chrysomelidae) larvae in the north central United States. Journal of Economic Entomology 90: 1332-1340.

Gómez S, Ferrieri RA, Schueller MJ \& Orians CM (2010) Methyl jasmonate elicits rapid changes in carbon and nitrogen dynamics in tomato. New Phytologist 188: 835-844.

Gray ME \& Steffey KL (1998) Corn rootworm (Coleoptera: Chrysomelidae) larval injury and root compensation of 12 maize hybrids: an assessment of the economic injury index. Journal of Economic Entomology 91: 723-740.

Hanik N, Gómez S, Best M, Schueller MJ, Orians CM \& Ferrieri RA (2010) Partitioning of new carbon as ${ }^{11} \mathrm{C}$ in Nicotiana tabacum reveals insight into methyl jasmonate induced changes in metabolism. Journal of Chemical Ecology 36: 1058-1067.

Hawkes CV \& Sullivan JJ (2001) The impact of herbivory on plants in different resource conditions: a meta-analysis. Ecology 82: 2045-2058.

Henkes GJ, Thorpe MR, Minchin PE, Schürr U \& Röse US (2008) Jasmonic acid treatment to part of the root system is consistent with simulated leaf herbivory, diverting recently assimilated carbon towards untreated roots within an hour. Plant, Cell and Environment 31: 1229-1236.

Hibbard BE, Higdon ML, Duran DP, Schweikert YM \& Ellersieck MR (2004) Role of egg density on establishment and plant-toplant movement by western corn rootworm larvae (Coleoptera: Chrysomelidae). Journal of Economic Entomology 9: 871-882.

Hibbard BE, Willmot DB, Flint-Garcia SA \& Darrah LL (2007) Registration of the maize germplasm CRW3(S1)C6 with resistance to western corn rootworm. Journal of Plant Registrations 1: 151-152.

Hibbard BE, Schweikert YM, Higdon ML \& Ellersieck MR (2008) Maize phenology affects establishment, damage, and development of the western corn rootworm (Coleoptera: Chrysomelidae). Environmental Entomology 37: 1558-1564.

Hilbert DW, Swift DM, Detling JK \& Dyer MI (1981) Relative growth-rates and the grazing optimization hypothesis. Oecologia 51: 14-18.

Holland JN, Cheng W \& Crossley DA (1996) Herbivore-induced changes in plant carbon allocation: assessment of belowground C fluxes using carbon-14. Oecologia 107: 87-94.

Howe GA \& Jander G (2008) Plant immunity to insect herbivores. Annual Review of Plant Biology 59: 41-66.

Hunter MD (2001) Out of sight, out of mind: the impacts of root-feeding insects in natural and managed systems. Agricultural and Forest Entomology 3: 3-9.

Jackson J \& Elliott NC (1988) Temperature-dependent development of immature stages of the western corn rootworm,
Diabrotica virgifera virgifera (Coleoptera: Chrysomelidae). Environmental Ecology 17: 166-171.

Lenth RV \& Hervé M (2015) lsmeans: least-squares means. R package version 1.10-4. Available at: http://CRAN.Rproject.org/package $=$ lsmeans (accessed May 2015).

Machado RA, Ferrieri AP, Robert CAM, Glauser G, Kallenbach $M$ et al. (2013) Leaf-herbivore attack reduces carbon reserves and regrowth from the roots via jasmonate and auxin signaling. New Phytologist 200: 1234-1246.

Mauricio R, Rausher MD \& Burdick DS (1997) Variation in the defense strategies of plants: are resistance and tolerance mutually exclusive? Ecology 78: 1301-1311.

McNaughton SJ (1979) Grazing as an optimization process grass ungulate relationships in the Serengeti. American Naturalist 113: 691-703.

Newingham BA, Callaway RM \& BassiriRad H (2007) Allocating nitrogen away from a herbivore: a novel compensatory response to root herbivory. Oecologia 153: 913-920.

Oleson JD, Park YL, Nowatzki TM \& Tollefson JJ (2005) Node-injury scale to evaluate root injury by corn rootworms (Coleoptera: Chrysomelidae). Journal of Economic Entomology 98: 1-8.

Paige KN \& Whitham TG (1996) Overcompensation in response to mammalian herbivory: the advantage of being eaten. American Naturalist 129: 407-416.

Pilson D (2000) The evolution of plant response to herbivory: simultaneously considering resistance and tolerance in Brassica rapa. Evolutionary Ecology 14: 457-489.

Prischmann DA, Dashiell KE, Schneider DJ \& Hibbard BE (2007) Field screening maize germplasm for resistance and tolerance to western corn rootworms (Col.: Chrysomelidae). Journal of Applied Entomology 131: 406-415.

Robert CAM, Erb M, Hibbard BE, French WB, Zwahlen C \& Turlings TCJ (2012a) A specialist root herbivore reduces plant resistance and uses an induced plant volatile to aggregate in a density-dependent manner. Functional Ecology 26: 14291440.

Robert CAM, Veyrat N, Glauser G, Marti G, Doyen GR et al. (2012b) A specialist root herbivore exploits defensive metabolites to locate nutritious tissues. Ecology Letters 15: 55-64.

Robert CAM, Ferrieri RA, Schirmer S, Babst BA, Schueller MJ et al. (2014) Induced carbon reallocation and compensatory growth as root herbivore tolerance mechanisms. Plant, Cell and Environment 37: 2613-2622.

Rogers RR, Owens JC, Tollefson JJ \& Witkowski JF (1975) Evaluation of commercial corn hybrids for tolerance to corn rootworms Diabrotica spp. (Coleoptera: Chrysomelidae). Environmental Entomology 4: 920-922.

Rogers RR, Russell WA \& Owens JC (1977) Expected gains from selection in maize for resistance to corn rootworms. Maydica 22: 27-36.

Russell WA, Owens JC, Peters DC \& Rogers RR (1976) Registration of maize germplasm. Crop Science 16: 886-887.

Salhuana W \& Pollak L (2006) Latin American Maize Project (LAMP) and Germplasm Enhancement of Maize (GEM) 
project: generating useful breeding germplasm. Maydica 51: 339-355.

Schultz JC, Appel HM, Ferrieri AP \& Arnold TM (2013) Flexible resource allocation during plant defense responses. Frontiers in Plant Science 22: 324.

Schwachtje J, Minchin PE, Jahnke S, van Dongen JT, Schittko U \& Baldwin IT (2006) SNF1-related kinases allow plants to tolerate herbivory by allocating carbon to roots. Proceedings of the National Academy of Sciences of the USA 103: 1293512940.

Stinchcombe JR (2002) Environmental dependency in the expression of costs of tolerance to deer herbivory. Evolution 56: 1063-1067.

Stowe KA, Marquis RJ, Hochwender CG \& Simms EL (2000) The evolutionary ecology of tolerance to consumer damage. Annual Review of Ecology and Systematics 31: 565-595.

Strauss SY \& Agrawal AA (1999) The ecology and evolution of plant tolerance to herbivory. Trends in Ecology and Evolution 14: 179-185.

Xue K, Serohijos RC, Devare MH, Duxbury JM, Lauren JG \& Thies JE (2012) Short-term carbon allocation and root lignin of Cry3Bb Bt and NonBt corn in the presence of corn rootworm. Applied Soil Ecology 57: 16-22.

\section{Supporting Information}

Additional Supporting Information may be found in the online version of this article:

Table S1. Mixed model table for maize root injury inflicted by Diabrotica virgifera.

Table S2. Mixed model table for root dry weight after 2 weeks infestation by Diabrotica virgifera.

Table S3. Mixed model table for root dry weight after 4 weeks infestation by Diabrotica virgifera.

Table S4. Mixed model table for root regrowth after 4 weeks infestation by Diabrotica virgifera.

Table S5. Mixed model table for plant stem circumference over time in the field (days 1-16).

Table S6. Mixed model table for plant stem circumference over time in the greenhouse (days 0-16).

Table S7. Mixed model table for the number of emerging crown roots over time in the field (days 0-12).

Table S8. Mixed model table for the number of emerging crown roots over time in the greenhouse (days 4-16). 